\title{
The effects of smoking on neutrophil/lymphocyte, platelet/ /lymphocyte ratios
}

\author{
Gumus $\mathrm{F}^{1}$, Solak $\mathrm{I}^{2}$, Eryilmaz $\mathrm{MA}^{3}$ \\ Department of Family Medicine, Konya Health Application and Research Center, University of Health Sciences, \\ Konya, Turkey. isolaktr@yahoo.com
}

\begin{abstract}
OBJECTIVE: The aim of this study was to compare the Neutrophil to Lymphocyte ratio (NLR), Platelet to Lymphocyte ratio (PLR) and Mean Platelet Volume to Platelet (MPV/PIt) ratio of smokers and non-smokers.

METHODS: Two hundred smokers and two hundred non-smoking healthy volunteers were enrolled in this study. Sociodemographic data and hematologic parameters of all patients were recorded. NLR, PLR and MPV/ Plt ratios were calculated.

RESULTS: The mean age of the case group was $35.88 \pm 10.56$ and the mean age of the control group was $38.97 \pm 10.56 .80 \%(n=160)$ of the smokers were male and $20 \%(n=40)$ were female. $27.5 \%(n=55)$ of the control group were male and $72.5 \%(n=145)$ were female. The smoker group had higher NLR and MPV/ PIt ratio $(p<0.05)$. PLR was significantly higher for the non-smoker group $(p<0.05)$.

CONCLUSION: As a result of our study, an increase in the NLR which is used as a systemic inflammatory marker, a decrease in the PLR and an increase in the MPV/PIt ratio which indicates thromboembolism risk were found for the smoker group (Tab. 3, Ref. 32). Text in PDF www.elis.sk.

KEY WORDS: neutrophil/lymphocyte ratio, platelet/lymphocyte ratio, smoking, mean platelet volume/platelet ratio.
\end{abstract}

\section{Introduction}

Smoking has been proven to increase systemic inflammation in previous studies using different biomarkers $(1,2)$. The neutrophil lymphocyte ratio (NLR) is calculated using neutrophil and lymphocyte numbers on a whole-blood test and now it is a popular indicator. NLR is considered to be an indicator of subclinical inflammation (3). Also recent studies have reported that high NLR is associated with increased cardiovascular risk and it is also related to increased mortality in some malignancies (4-6). The mean platelet volume (MPV) and platelet lymphocyte ratio (PLR) that are indicators of the increased platelet activation have been associated with the onset and progression of atherosclerosis (7).

Despite of the fact that its cause and mechanisms are not clearly known, acute smoking causes increase in leukocyte, eosinophil and platelet counts in peripheral blood. It has been reported that blood test results return to normal range after 5 years of cessation (8). Various studies have shown that white cell counts, differen-

\footnotetext{
${ }^{1}$ Department of Family Medicine, Konya Health Application and Research Center, University of Health Sciences, Konya, Turkey, ${ }^{2}$ Department of Family Medicine, Konya Health Application and Research Center, University of Health Sciences, Konya, Turkey, and ${ }^{3}$ Department of General Surgery, Konya Health Application and Research Center, University of Health Sciences, Konya, Turkey
}

Address for correspondence: I. Solak, MD, Department of Family Medicine, Konya Health Application and Research Center, University of Health Sciences, Konya, Turkey.

Phone: 0533.6591171 tial leukocyte percentages and thrombocyte activity markers are impaired due to smoking $(9,10)$.

Recently, several studies have been conducted on NLR and PLR, which are used as systemic inflammatory markers and are used to monitor prognosis, morbidity and mortality of many diseases $(11,12)$. Although there are many studies exploring the effects of smoking on hemogram parameters, there is limited number of studies carried out to find out the effects of smoking on NLR, PLR, MPV/Platelet (MPV/Plt) ratios.

A complete blood count test can easily be performed in all cheap laboratories. NLR, PLR, MPV/Plt ratio and other wholeblood counts can be evaluated by clinicians using a method which is quick and cheap.

The aim of our study was to investigate the effects of smoking, the amount of cigarettes smoked and smoking duration on the following values: NLR, TLR and MPV / Plt ratios.

\section{Material and methods}

This prospective study was approved by the Ethics Committee of the Department of Medicine of Necmettin Erbakan University by decision no. 492 dated 4 November 2015. The patients who applied to the Family Medicine Clinics of Konya Training and Research Hospital, Health Sciences University, for smoking cessation and the control group were all informed about the study. The participants had to sign an approval form which is prepared according to the World Medical Association Declaration of Helsinki. Participants were asked to fill out a questionnaire. The 
Tab. 1. Socio-demographic characteristics of the participants.

\begin{tabular}{|c|c|c|c|c|c|c|}
\hline & & \multicolumn{2}{|c|}{$\begin{array}{l}\text { Smoker } \\
(\mathrm{n}=200)\end{array}$} & \multicolumn{2}{|c|}{$\begin{array}{c}\text { Non-Smoker } \\
(\mathrm{n}=200)\end{array}$} & \multirow[t]{2}{*}{$\mathrm{p}$} \\
\hline & & $\mathrm{n}$ & $\%$ & $\mathrm{n}$ & $\%$ & \\
\hline \multirow{2}{*}{ Gender } & Male & 160 & 80 & 55 & 27.5 & \multirow{2}{*}{0.001} \\
\hline & Female & 40 & 20 & 145 & 72.5 & \\
\hline \multirow{2}{*}{ Marital Status } & Married & 151 & 75.5 & 162 & 81 & \multirow{2}{*}{0.182} \\
\hline & Single & 49 & 24.5 & 38 & 19 & \\
\hline \multirow{5}{*}{ Occupation } & Housewife & 24 & 12 & 64 & 32 & \multirow{5}{*}{0.001} \\
\hline & Civil Servant & 18 & 9 & 21 & 10.5 & \\
\hline & Retired & 7 & 3.5 & 15 & 7.5 & \\
\hline & Worker & 57 & 28.5 & 4 & 2 & \\
\hline & Others & 94 & 47 & 96 & 48 & \\
\hline \multirow{2}{*}{ Education } & Middle School or Less & 113 & 56.5 & 53 & 26.5 & \multirow{2}{*}{0.001} \\
\hline & High School or More & 87 & 43.5 & 147 & 73.5 & \\
\hline
\end{tabular}

questionnaire was read audibly for the illiterate participants and marked by the researcher. Those who left unanswered questions on the questionnaire were excluded from the study.

The study was conducted with people between the ages of 18 and 65 who agreed to participate. The case group consisted of smokers who smoked at least 5 pack years and the control group consisted of the participants who have never smoked. Since inflammation and hematological parameters could be affected, the patients with anemia, leukocytosis, leukopenia, obesity (BMI $\geq$ 30), pregnancy, alcohol consumption, malignancy, drug use history (aspirin, clopidogrel, steroid), blood transfusion in the last 3 months, upper respiratory tract infection, inflammation and hematological parameters of patients with chronic illnesses (diabetes mellitus, systemic or pulmonary hypertension, hypothyroidism, hyperthyroidism, renal failure, idiopathic thrombocytopenic purpura, chronic obstructive pulmonary disease, asthma, hyperlipidemia, coronary artery disease, heart failure, chronic liver disease) were excluded from this study.

\section{Analysis of laboratory investigations}

Venous blood samples were taken in a purple capped tube containing ethylenediaminetetraacetic acid (EDTA) from the participants. For full blood count; $0.5-2 \mathrm{ml}$ of blood was sampled in a Sysmex XT 2000i (Roche Diagnostics GmbH, Mannheim, Germany).

\section{Statistical analysis}

SPSS 22.0 package program was used to enter the collected data and to analyze them. Descriptive statistics of the categorical data were shown using frequency and percentage values while the statistics of the numerical data were shown using mean and standard deviation. Kolmogorov-Smirnov and Shapiro Wilk tests' distribution charts were used to evaluate whether the numerical data conform to the normal distribution. T test was utilized to analyze the continuous data which conform to the normal distribution. For the data which do not conform to the normal distribution, MannWhitney U analysis method was used to compare two groups while Kruskal-Wallis analysis method was used for multiple groups. For statistical significance, $\mathrm{p}<0.05$ value was chosen.

\section{Results}

200 smokers were included in the case group while 200 nonsmokers were selected as the control group. The socio-demographic characteristics of the participants are given in Table 1. Age $(\mathrm{p}=$ $0.011), \operatorname{WBC}(\mathrm{p}=0.001), \operatorname{RBC}(\mathrm{p}=0.001)(\mathrm{p}=0.001), \operatorname{Hct}(\mathrm{p}=$ $0.001), \operatorname{MPV}(p=0.001)$, Lymphocyte $(\mathrm{p}=0.006)$, Eosinophil $(\mathrm{p}$ $=0.001)$, Neutrophil $(\mathrm{p}=0.001)$, RDW $(\mathrm{p}=0.001)$ values were found to be significantly higher for the smokers yet Plt $(p=0.013$ ) was significantly lower for them. There was no significant difference between MCV and BMI values between the two groups ( $p$ $=0.348)$ (Tab. 2).

$\operatorname{NLR}(p=0,031)$ and MPV/Plt $(p=0.001)$ ratios were found to be significantly higher for the smoker group but PLR $(p=0.001)$ value was significantly lower for them (Tab. 3).

Tab. 2. Data comparison for the control and case groups.

\begin{tabular}{lccc}
\hline & $\begin{array}{c}\text { Smokers } \\
(\mathrm{n}=200) \\
\text { Mean } \pm \text { Std }\end{array}$ & $\begin{array}{c}\text { Non-Smokers } \\
(\mathrm{n}=200) \\
\text { Mean } \pm \text { Std }\end{array}$ & $\mathrm{p}$ \\
\hline Age & $35.88 \pm 0.47$ & $38.98 \pm 0.84$ & 0.011 \\
BMI & $24.24 \pm 0.25$ & $24.05 \pm 0.20$ & 0.875 \\
WBC $\left(/ \mathrm{mm}^{3}\right)$ & $8.04 \pm 1.75$ & $7.02 \pm 1.73$ & 0.001 \\
$\mathrm{RBC}(\mathrm{K} / \mathrm{ul})$ & $5.27 \pm 0.51$ & $4.77 \pm 0.42$ & 0.001 \\
$\mathrm{Hb}(\mathrm{g} / \mathrm{dl})$ & $15.48 \pm 1.47$ & $13.60 \pm 1.28$ & 0.001 \\
Hct $(\%)$ & $45.25 \pm 3.58$ & $40.77 \pm 3.28$ & 0.001 \\
MCV $(\mathrm{fl})$ & $86.09 \pm 6.07$ & $85.82 \pm 5.48$ & 0.348 \\
Plt $(\mathrm{K} / \mathrm{ul})$ & $243.86 \pm 60.03$ & $258.92 \pm 62.54$ & 0.013 \\
MPV $(\mathrm{fl})$ & $10.54 \pm 0.85$ & $9.69 \pm 1.43$ & 0.001 \\
Lymphocyte $\left(/ \mathrm{mm}^{3}\right)$ & $2.46 \pm 0.63$ & $2.34 \pm 0.73$ & 0.006 \\
Eosinophil $\left(/ \mathrm{mm}^{3}\right)$ & $0.18 \pm 0.12$ & $0.15 \pm 0.14$ & 0.001 \\
Neutrophil $\left(/ \mathrm{mm}^{3}\right)$ & $4.72 \pm 1.43$ & $4.05 \pm 1.26$ & 0.001 \\
RDW $(\%)$ & $14.06 \pm 1.52$ & $13.54 \pm 1.23$ & 0.001 \\
\hline
\end{tabular}

Tab. 3. Comparison of NLR, PLR and MPV/PIt Ratios for Control and Case Groups.

\begin{tabular}{lccc}
\hline & $\begin{array}{c}\text { Smokers }(\mathrm{n}=200) \\
\text { Mean } \pm \text { Std }\end{array}$ & $\begin{array}{c}\text { Non-Smokers }(\mathrm{n}=200) \\
\text { Mean } \pm \text { Std }\end{array}$ & $\mathrm{p}$ \\
\hline NLR & $2.10 \pm 1.42$ & $1.87 \pm 0.83$ & 0.031 \\
PLR & $109.76 \pm 90.77$ & $118.66 \pm 40.20$ & 0.001 \\
MPV/Plt Ratio & $0.04 \pm 0.01$ & $0.03 \pm 0.012$ & 0.001 \\
\hline
\end{tabular}


116-119

The smoker group was divided into two groups: the first group consisted of participants who had smoked less than 20 pack-years and the second group consisted of participants who had smoked more than 20 pack-years. No statistically significant difference between the two groups was found for the following values, NLR $(p=0.090), \operatorname{PLR}(p=0.250)$, MPV/Plt ratio $(p=0.390)$.

The smoker group was divided into three groups according to the number of cigarettes smoked per day: 1-10 per/day, 11-20 per/ day and more than 20 per/day. No statistically significant difference between the three groups was found for the following values, $\operatorname{NLR}(p=0.422), \operatorname{PLR}(p=0.524)$, MPV/Plt ratio $(p=0.067)$.

\section{Discussion}

Smoking is recognized as a high risk factor for cardiovascular diseases, hypertension, inflammation, stroke, coagulopathy and respiratory diseases (13). Moreover, some studies have reported that smoking accelerates cancer formation in various organs such as lung, pancreas, kidney and liver $(14,15)$. The effects of smoking on the hematopoietic system have been shown in several studies $(16,17)$. However, there are few studies carried out to evaluate the effect of smoking on NLR, PLR and MPV / Plt ratios.

Recently, NLR and PLR values have been associated with malignancies, diabetes mellitus, Chronic Obstructive Pulmonary Disease (COPD), systemic inflammatory response in rheumatic diseases (4). Those values also correlate with prognosis, morbidity and mortality in many diseases (cardiovascular disease, pulmonary, infections, endocrine disorders and some cancers) $(5,6,18)$.

Increased number of neutrophils at high NLR levels depends on increased inflammation, low lymphocyte counts depend on general health impairment, increased cortisol levels due to physiological stress, and increased apoptosis (19). Kizilarslanoglu et al (20) investigated whether COPD can be predicted in geriatric patients using NLR in a study that included 507 patients. According to the results of this study, NLR values of geriatric patients with COPD were found to be high and this new marker could be an independent risk factor for COPD in geriatric patients. The retrospective study carried out by Tulgar et al (21) showed that the NLR of smokers was significantly higher. Similarly, in our study, NLR was found significantly higher in smokers. Aydin et al (22) carried out a study in 71.897 patients and reported that NLR value increases until the 20 s then it remains stable but it rises again after age 60 . In this study, the mean age of the non-smoker group $(38.98 \pm 0.84)$ was found to be statistically higher than the mean age of the smoker group $(35.88 \pm 0.47)$. It can be said that since the mean age of participants is in the range of 35-40, age does not affect the NLR value.

Similar to NLR, PLR, which is also an indicator of inflammation, is a routine part of a blood test results without additional cost (23). Thrombocytosis and lymphopenia have been associated with systemic inflammatory response and PLR has begun to be used as a new marker to combine both hematological indicators (24). Active thrombocytes cause inflammatory mediator release from endothelial cells and leukocytes and increase monocyte adhesion and transmigration which leads to a stronger inflamma- tory response. Kim et al (25) reported that PLR could be used as a mortality predictor in cardiac, pulmonary and some oncological diseases. A retrospective study carried out by Tulgar et al (21) found smokers' PLR to be lower but no statistically significant difference was observed. In our study, the PLR values of smokers were statistically significantly lower. The reason for the lower values of PLR in the smoker group was that the number of platelet counts was low in smokers.

Chronic smoking is an important but changeable risk factor for cardiovascular diseases (26). Smoking accelerates atherosclerosis; it also causes endothelial dysfunction and hemostatic disorders (27). Mean platelet volume (MPV) is a potential marker of platelet activation (28). MPV levels are elevated in thromboembolic diseases (29). In the case of venous thromboembolism, large platelets in bone marrow are released and thrombopoiesis is induced via inflammatory cytokines such as IL-1, IL-6 and TNF alpha. Thromboxane A2, platelet factor 4, thromboglobulin, adenosine triphosphate, and many other substances are released from large thrombocytes (30).

Ozoguz et al (31) investigated the MPV / Plt ratio which tends to coagulate in a study of 85 Behcet's patients and 40 healthy volunteers. Patients with deep vein thrombosis (DVT) history were reported to have significantly higher rates of MPV and MPV / Plt. Braekkan et al (32) conducted a prospective, population-based study of 25.923 adults; they investigated the effect of platelet count and MPV on DVT. They reported that there was a significant negative correlation between MPV and platelet count; also that increased MPV caused increased DVT risk. In our study, MPV and MPV / Plt ratio were significantly higher in smokers whereas platelet count was significantly lower. These findings support the increased risk of DVT in smokers.

\section{Conclusions}

In this study, we identified an increase in the NLR which is used as a systemic inflammatory marker, a decrease in the PLR and an increase in the MPV/Plt ratio which indicates thromboembolism risk found in the smoker group. Smoking may contribute to the onset and progression of many physiologic-pathological processes in healthy or clinically asymptomatic smokers.

\section{References}

1. Yanbaeva DG, Dentener MA, Creutzberg EC, Wesseling G, Wouters EF. Systemic effects of smoking. Chest J 2007; 131 (5): 1557-1566.

2. Levitzky YS, Guo C-Y, Rong J, Larson MG, Walter RE, Keaney JF et al. Relation of smoking status to a panel of inflammatory markers: the Framingham offspring. Atherosclerosis 2008; 201 (1): 217-224.

3. Zahorec R. Ratio of neutrophil to lymphocyte counts-rapid and simple parameter of systemic inflammation and stress in critically ill. Bratisl Lek Listy 2001; 102 (1): 5-14.

4. Uslu AU, Küçük A, Şahin A, Ugan Y, Yilmaz R, Güngör T et al. Two new inflammatory markers associated with Disease Activity Score-28 in patients with rheumatoid arthritis: neutrophil-lymphocyte ratio and plateletlymphocyte ratio. Int J Rheum Dis 2015; 18 (7): 731-735. 
5. Peng B, Wang Y-H, Liu Y-M, Ma L-X. Prognostic significance of the neutrophil to lymphocyte ratio in patients with non-small cell lung cancer: a systemic review and meta-analysis. Int J Clin Exp Med 2015; 8 (3): 3098.

6. Tan TP, Arekapudi A, Metha J, Prasad A, Venkatraghavan L. Neutrophil-lymphocyte ratio as predictor of mortality and morbidity in cardiovascular surgery: a systematic review. ANZ J Surg 2015; 85 (6): 414-419.

7. Tamhane UU, Aneja S, Montgomery D, Rogers E-K, Eagle KA, Gurm HS. Association between admission neutrophil to lymphocyte ratio and outcomes in patients with acute coronary syndrome. Amer J Cardiol 2008; 102 (6): 653-657.

8. Bain B, Rothwell M, Feher M, Robinson R, Brown J, Sever P. Acute changes in haematological parameters on cessation of smoking. J Royal Soc Med 1992; 85 (2): 80-82.

9. Lee S, Hizoh I, Kovacs A, Horvath Z, Kiss N, Toth-Zsamboki E et al. Predictors of high on-clopidogrel platelet reactivity in patients with acute coronary syndrome. Platelets 2016; 27 (2): 159-167.

10. Sharma KH, Shah KH, Patel I, Patel AK, Chaudhari S. Do circulating blood cell types correlate with modifiable risk factors and outcomes in patients with acute coronary syndrome (ACS)? Indian Heart JCardiovasc Dis 2016; 16 (1): 123.

11. Raffetti E, Donato F, Casari S, Castelnuovo F, Sighinolfi L, Bandera $\mathbf{A}$ et al. Systemic inflammation-based scores and mortality for all causes in HIV-infected patients: a MASTER cohort study. BMC Infect Dis 2017; 17 (1): 193.

12. Aggarwal A, Aggarwal S, Sarkar PG, Sharma V. Predisposing factors to premature coronary artery disease in young (age $\leq 45$ years) smokers: a single center retrospective case control study from India. J Cardiovasc Thor Res 2014; 6 (1): 15.

13. Abel GA, Hays JT, Decker PA, Croghan GA, Kuter DJ, Rigotti NA, editors. Effects of biochemically confirmed smoking cessation on white blood cell count. Mayo Clinic Proceedings; 2005: Elsevier.

14. Wannamethee SG, Lowe GD, Shaper AG, Rumley A, Lennon L, Whincup PH. Associations between cigarette smoking, pipe/cigar smoking, and smoking cessation, and haemostatic and inflammatory markers for cardiovascular disease. Eur Heart J 2005; 26 (17): 1765-1773.

15. Inal B, Hacibekiroglu T, Cavus B, Musaoglu Z, Demir H, Karadag B. Effects of smoking on healthy young men's hematologic parameters. Northern Clin Istanbul. 2014; 1 (1): 19.

16. Lakshmi A, Anandhi Lakshmanan GKP, Saravanan A. Effect of intensity of cigarette smoking on haematological and lipid parameters. J Clin Diagn Res JCDR. 2014; 8 (7): BC11.

17. Salciccioli JD, Marshall DC, Pimentel MA, Santos MD, Pollard T, Celi LA et al. The association between the neutrophil-to-lymphocyte ratio and mortality in critical illness: an observational cohort study. Crit Care 2015; 19 (1): 13.

18. Azab B, Daoud J, Naeem FB, Nasr R, Ross J, Ghimire $P$ et al. Neutrophil-to-lymphocyte ratio as a predictor of worsening renal function in diabetic patients (3-year follow-up study). Renal Failure 2012; 34 (5): 571-576.
19. Kizilarslanoglu Mc, Kuyumcu Me, Kilic Mk, Neutrophil To Lymphocyte Ratio May Predict Coronary Artery Disease In Geriatric Patients. Acta Med 2015 4: P. 58-63.

20. Tulgar Y, Cakar S, Tulgar S, Dalkilic O, Cakiroglu B, Uyanik B. The effect of smoking on neutrophil/lymphocyte and platelet/lymphocyte ratio and platelet indices: a retrospective study. Eur Rev Med Pharmacol Sci 2016; 20 (14): 3112-3118.

21. Aydin I, Ağilli M, Aydin FN, Kurt YG, Çayci T, Taş A et al. Farkli yaş gruplarinda nötrofil/lenfosit orani referans araliklari. Gulhane Medl J 2015; 57 (4).

22. Messager M, Neofytou K, Chaudry M, Allum W. Prognostic impact of preoperative platelets to lymphocytes ratio (PLR) on survival for oesophageal and junctional carcinoma treated with neoadjuvant chemotherapy: a retrospective monocentric study on 153 patients. Eur J Surg Oncol (EJSO). 2015; 41 (10): 1316-1323.

23. Şener A, Sivri HDÇ, Sivri S, Ertem AG, Çelik GK, Köseoğlu C et al. The Prognostic Value of The Platelet/Lymphocyte Ratio in Predicting Short-Term Mortality in Patients with Acute Pulmonary Embolism. Sakarya Tip Dergisi 2015; 5 (4).

24. Kim DS, Shin D, Lee MS, Kim HJ, Kim DY, Kim SM et al. Assessments of neutrophil to lymphocyte ratio and platelet to lymphocyte ratio in Korean patients with psoriasis vulgaris and psoriatic arthritis. $\mathrm{J}$ Dermatol 2016; 43 (3): 305-310.

25. Erhardt L. Cigarette smoking: an undertreated risk factor for cardiovascular disease. Atherosclerosis 2009; 205 (1): 23-32.

26. Caponnetto P, Russo C, Di Maria A, Morjaria JB, Barton S, Guarino $\mathbf{F}$ et al. Circulating endothelial-coagulative activation markers after smoking cessation: a 12-month observational study. Eur J Clin Invest 2011; 41 (6): 616-626.

27. Park Y, Schoene N, Harris W. Mean platelet volume as an indicator of platelet activation: methodological issues. Platelets 2002; 13 (5-6): 301-306.

28. Gulcan M, Varol E etli M, Aksoy F, Kayan M. Mean platelet volume is increased in patients with deep vein thrombosis. Clin Appl Thromb Hemost 2012; 18 (4): 427-430.

29. Cho S, You E, Lee H, Lee W, Park T. Smoking cession decreases mean platelet volume in healthy Korean populations. Clin Labor 2014; 60 (8): 1413.

30. Ozuğuz P, Kacar SD, Akci Ö, Balta İ, Karaca S, Kocak M. Behçet hastaliğinin aktivitesini daha pratik ve kolay yöntemlerle belirleyebilir miyiz? Gulhane Med J 2014; 56 (4): 213-217.

31. Braekkan S, Mathiesen E, Njølstad I, Wilsgaard T, Størmer J, Hansen $\mathbf{J}$. Mean platelet volume is a risk factor for venous thromboembolism: the Tromsø study. J Thromb Haemost 2010; 8 (1): 157-1562.

Received October 23, 2017. Accepted November 17, 2017. 